\title{
"Eu? Eu estou aí, compondo o mundo." Uma experiência de controle de endemia, pesquisa e participação popular vivida em Cansanção, Minas Gerais, Brasil
}

\author{
"Me? I'm just here, part of the world". \\ A field experience on endemic disease control \\ in Cansanção, Minas Gerais, Brazil
}

Rosinha Borges Dias 1

\footnotetext{
1 Departamento de Serviço Social, Pontifícia Universidade Católica de Minas Gerais. Rua Ipê Branco 467, Retiro das Pedras, Belo Horizonte, $M G$ 30140-970, Brasil.
}

\begin{abstract}
This article reports an experience with Chagas' disease control involving community participation in the Jequitinhonha Valley (Minas Gerais, Brazil) implemented during the 1980s, as an action-based participant research project of Popular Education. The main objective was to investigate the meaning of Chagas' disease from the community's perspective, seeking alternative control measures with their participation. Despite the extremely high prevalence of the disease, it was no perceived as a priority by the population, who were living in destitution and simply fighting for their very survival. Chagas' disease control was performed in an integrated manner, taking other community needs into account. The article suggests some forms of participation in the control of endemic diseases, taking into account the people's knowledge, in an integrated vision of both their problems and their ability to mobilize behind concrete interests. Changes are also needed in the relationship between outside agents and the community, reciprocity in the involvement with community, a permanent attitude of listening and solidarity, a "self-diagnosis", and organization of population.
\end{abstract}

Key words Consumer Participation; Community Participation; Chagas' Disease; Health Education; Communicable Disesase Control

Resumo Este artigo relata uma experiência de controle da doença de Chagas, vivida na década de 80 em um povoado rural do Vale do Jequitinhonha, MG, e reavaliada recentemente. Trata-se de um projeto de pesquisa-ação participativa, com aplicação na área de educação popular em saúde. Teve como objetivo conhecer, do ponto de vista dos sujeitos, o significado da doença de Chagas na vida de uma comunidade endêmica, procurando com eles alternativas de controle. Apesar da altíssima prevalência, a doença não chegava a ser prioridade sentida pela população, que vivia em situação de carências múltiplas e de luta pela sobrevivência. O controle da doença deu-se de forma integrada com outras necessidades. Levantam-se pistas para trabalhos de participação no controle de endemias, levando-se em conta a sabedoria popular, a visão integrada dos problemas e na mobilização em torno de interesses concretos. Destacam-se como necessários: a mudança nas relações entre o agente externo e a comunidade, a reciprocidade do envolvimento, a postura de 'escuta' e de solidariedade, o autodiagnóstico, a organização da população. Palavras-chave Participação Comunitária; Doença de Chagas; Educação em Saúde; Controle de Doenças Transmissíveis 


\section{Introdução}

Quando me lembro de Cansanção, sempre me vem um calorzinho bom ao coração e alguma clareza à mente. À respeito do tema participação, vem a minha cabeça uma expressão ouvida de dona Teresa, mulher de idade indefinida, chefe de família, trabalhadora de enxada, raizeira e 'aparadora de menino' (parteira), que morava em uma das grotas de Cansanção, chamada Quilombo. Em uma das vezes em que nossa equipe lá acabara de chegar de Belo Horizonte, para passar três dias com eles, encontramos a senhora andando pelas trilhas da roça e, alegres, cumprimentamo-la: "E aí, D. Teresa, tudo bem? Como vai passando?" Ela nos olhou e, sorrindo com os olhos, respondeu com essa expressão tão bonita: " $E u$ ? Eu, tô aí, compondo o mundo". E realmente estava 'compondo o mundo', participando, fazendo a sua parte para que o mundo fosse melhor ali, onde ela sempre viveu. A participação passa pela descoberta de que somos parte de um todo maior que nossa pessoa, família ou comunidade; parte desse 'mundão de Deus', dessa imensa vida que circula nos seres da natureza e por todo universo. E que, por isso mesmo, devemos fazer a nossa parte para que esse mundo seja mais humano e livre do que é. Às vezes é quase nada o que fazemos, mas estamos dando a nossa participação.

De 1982 a 1985, desenvolvemos um projeto de pesquisa-ação, ou pesquisa participante, na localidade de Cabeceira do Cansanção, situada no Município de Minas Novas, Vale do Jequitinhonha, MG. Tal projeto foi patrocinado pelo Comitê de Pesquisas Econômico-Sociais em Doenças Tropicais da Organização Mundial da Saúde (WHO/TDR/Ser) e pela Universidade Católica de Minas Gerais (Puc/MG). O tema do projeto foi Doença de Chagas: Conhecimento Popular e Novas Estratégias de Controle.

Passados dez anos do término do projeto, fomos convidadas pelo Setor de Educação em Saúde do Distrito Sanitário de Curvelo, da Fundação Nacional de Saúde (FNS), para visitar a localidade novamente, avaliando as mudanças ocorridas e oferecendo subsídios metodológicos para o trabalho de Mobilização Comunitária que o setor desenvolve em sessenta municípios do Estado. Para atender a essa demanda, algumas atividades foram realizadas: reuniões com educadores da FNS em Belo Horizonte, viagem e visita à área em julho de 96, participação em uma reunião do Conselho Municipal de Saúde de Minas Novas. Na visita a Cansanção, tivemos oportunidade de ter dois encontros com a população em geral, fizemos algu- mas entrevistas informais com lideranças locais, visitas às creches, reunião com o conselho da Associação de Moradores e recebemos um folheto por eles escrito, entitulado Cansanção $e$ o Progresso.

O presente texto conta um pouco dessa história, com destaques para as falas da população. Faremos uma síntese do que foi o projeto desenvolvido há dez anos e a situação atual de Cansanção. No final, apontamos algumas lições aprendidas sobre participação popular no controle das endemias.

\section{O que foi o trabalho há dez anos}

\section{Os propósitos do projeto}

A experiência de pesquisa-ação participativa vivida de 82 a 85 em Cansanção combinou atividades de pesquisa sócio-antropológica, ação participativa e controle de doença endêmica. O objetivo era conhecer mais profundamente o 'palco' clássico onde a doença de Chagas acontece, do ponto de vista dos sujeitos, procurando com eles alternativas de controle, bem como conhecer o que pensavam os moradores sobre suas condições de vida, de trabalho, de saúde/doença, os problemas que enfrentavam no seu dia-a-dia, as relações que estabeleciam entre os diversos aspectos do cotidiano e, juntos, procurar saídas. Algumas perguntas nos moviam: Que significado teria a doença de Chagas na vida de uma comunidade rural, onde $71 \%$ das pessoas acima de 15 anos são positivas para o Trypanosoma cruzi? Se lhes fossem dados ouvido e direito de opinar, que medidas adotariam para o controle da doença? Mais do que um produto final, com resultados provados, tratou-se de um processo participado de conhecer e agir.

\section{Breve quadro da realidade}

Na época do projeto, Cansanção era uma localidade rural dispersa, abrangendo 146 famílias, que viviam em várias comunidades ou grotas adjacentes: Tabuleiro, Cristal, Campinho, Quilombo, Cabeceira, Borges e Fazenda. Além da doença de Chagas, apresentavam alta incidência de esquistossomose, várias parasitoses intestinais e também casos de tuberculose e outras doenças infecciosas, como a leishmaniose.

Eram todos pequenos (micro) proprietários, produzindo basicamente milho, mandioca e feijão, em quantidade insuficiente para a reprodução da família. Desde o final da década de 60 , usavam como estratégia de sobrevivên- 
cia a migração sazonal dos homens para trabalhar na usinas de álcool e açúcar da região de Ribeirão Preto, SP. Viviam assim uma situação ambígua: eram produtores diretos na agricultura durante o tempo das águas e assalariados temporários na indústria no tempo da seca. Tinham contato com uma realidade pré-moderna e outra quase pós-moderna. As mulheres tinham um papel-chave na preservação da vida no lugar, representando o elo com a terra e sua condição de proprietários. Contudo, esta separação era vivida com muito sofrimento.

A localidade não contava com postos de saúde. Na sede do Município (que situa-se a 39 km de distância em estrada de terra muito precária) existia um pequeno hospital. Não havia transporte coletivo, nem morador que possuísse carro. A comunicação era feita a pé ou a cavalo. A escola contava apenas com uma professora, que atendia ao mesmo tempo 92 alunos das três primeiras séries.

Apesar da altíssima prevalência da doença de Chagas entre os moradores, $71 \%$ entre os maiores de 15 anos, o tratamento desta não chegava a ser sentido como prioritário pela população. Era apenas mais um problema, que ficava obscurecido diante da cotidiana luta pela sobrevivência: ter o que comer no dia seguinte e aliviar as dores que os atrapalhavam de trabalhar.

A seguir, algumas expressões dos moradores sobre sua condição de vida que nos tocavam profundamente e nos punham a pensar.

"Nós vamos levando a vida assim: trabalhando e tratando da obrigação. Planta milho, feijão, mandioca, cana, banana, arroz (...). Planta tudo que fala que é manso. Plantar é a vida e se não cuidar de tudo isso, passa fome. Tenho família grande, todos têm que trabalhar, senão passa fome."

"Nossa situação é de doença e de fraqueza, mas mais de fraqueza." O termo fraqueza é usado por eles para se referir à pobreza associada ao sentimento de impotência de lutar contra ela.

"Nós tudo aqui vive é da enxada, com a força dos braços, gastando o corpo."

"O que mata não é a fome, é o pensamento. Eu vou para São Paulo e fico de lá, pensando na mulher e nas crianças. E ela de cá, preocupada comigo lá."

"Mulher é bicho atolado, carregado de filho, homem é andejo, despreocupado."

"A vida aqui é mais apertada, mas é mais livre. Tudo aqui é ruim, só é bom de amigo.”

"Ah,... eu sonho tanta coisa que nem é bom repartir (...). Favorecimento pra gente (...) Quem tá atolado num buraco quer sair, não é? Quero vida com saúde, felicidade. Quero trabalhar sem sentir nada."

"Quem tem estudo é mais importante do que quem não tem. Aliás, quem tem estudo e um pedacinho de terra, tem tudo. Nós só temos a força dos braços."

\section{O processo de trabalho}

De maneira sintética, vamos descrever o processo metodológico em algumas etapas, que na realidade não aconteceram de forma linear, mas de modo dinâmico e muitas vezes concomitantes. O processo iniciou-se com a trabalhosa e fascinante etapa de conhecer e dar-se a conhecer, através de visitas domiciliares a todas as famílias, conversas informais, observação participante, entrevista aberta e convivência com os moradores. Nossa equipe ia à cidade uma vez ao mês e se hospedava com eles. Os moradores viram assim este começo:

"Primeiramente elas andaram pelas casas dando explicação do trabalho e fazendo perguntas. Chegaram e foram tomando conhecimento com a gente, e a gente também com elas."

"No começo o povo tinha medo das perguntas, não sabiam (...). Muitos ficaram acismados, mas foram amansando..."

"Quando elas começaram eu achei um caso muito importante. Elas vieram na minha casa. Antes a gente pensava que nós aqui era bicho do mato pro pessoal da cidade, que ignora a gente. Parece que não somos da qualidade deles. Com elas foi diferente. Tratava nós tudo por igual, sem fazer pouco caso."

"A gente fica muito importante porque as pessoas que vêm, dizem que vêm para aprender mesmo."

De cada família, foi preenchido um formulário com os dados usuais: idade, parentesco, ocupação, educação, características da habitação, produção, e mais a opinião deles sobre a doença de Chagas, o barbeiro (chupão) e os principais problemas do lugar. Foram feitos exames de fezes e de sangue e consulta médica aos que assim quiseram.

A etapa seguinte foi de sistematização e devolução destes dados para os moradores. Foi desencadeado um processo de reflexão sobre os principais problemas apontados nas entrevistas e suas causas. Discutiram as prioridades, levando em consideração a gravidade e urgência dos problemas diante do pequeno alcance do projeto. Apontaram alternativas sobre o que fazer para enfrentar aquela situação. Houve oportunidade concreta de escolha e tomada de decisão coletiva sobre as ações que foram implementadas ali, com a co-gestão deles, durante mais de dois anos do projeto. 
Aqui cabe um esclarecimento: quando foi feito o pedido de financiamento do projeto de pesquisa-ação à OMS (TDR/Ser), foi destinada uma quantia (cerca de dois mil dólares) para um pequeno programa comunitário de controle da doença de Chagas. Deu-se à comunidade a oportunidade de opinar, decidir em assembléia e encaminhar o gasto deste recurso (Dias, 1986).

Como na visão deles a doença de Chagas não está desvinculada das condições gerais de vida, as ações do programa comunitário giraram em torno de três eixos principais: saúde, melhoria na produção de alimentos e cidadania. As principais demandas de saúde foram: ter acesso à assistência médica (visita do médico uma vez ao mês), exames de sangue, fezes, remédios, filtros domésticos, melhoria de habitação e treinamento de agentes populares de saúde. As demandas de melhoria da produção de alimentos foram sementes de milho, feijão, hortaliças, arado com junta de bois, mangueiras para água. As outras demandas referiam-se ao registro civil, materiais de construção de um salão comunitário, cursos de alfabetização de adultos, costura e bordado. Aos poucos, foi acontecendo uma outra organização da comunidade: primeiro em um conselho de representantes de cada grota, mais tarde, em uma associação de moradores.

Podemos notar que as atividades do programa comunitário tiveram alguma lógica, podendo ser organizadas em três grupos de naturezas diferentes: remediando situações (assistência médica etc.), lutando pelas mudanças (melhoria na produção de alimentos, nas moradias) e despertando a consciência/cidadania (cursos, treinamentos/criação de conselho de representantes, registro civil).

"Eu nunca tinha ouvido falar de reunião. Imagina, uma mulher velha como eu, ainda não sabia de reunião."

"Antes a gente passava até um ano sem ver ninguém, cada um na sua roça. Dia de domingo a gente tava com o corpo quebrado. Nós não conhecia este negócio de reunião."

"Falava doença de Chagas e eu não compreendia o que era, não sabia o quê. Escutava e ficava sem saber. Sabia que o chupão ofendia, mas pensava que era igual formiga, mordia e não fazia nada. Era mal passageiro. Não pensava que o chupão ofendia pra fazer doença. Tinha doença e não sabia por quê."

"Tudo muito interessante e se todo mundo acompanhar vai ficar bonito. Porque esse trabalho está sendo uma escola - a pessoa compreende mais um tiquinho. Agora a gente já sabe fazer reunião. Por exemplo: se cada um vai vender seu produto na cidade, cada um pega um preço muito menor. Mas, se tem união, todo mundo reúne para vender e faz o mesmo preço. Porque o comerciante compra por pouco o que nós produz e vende por muito. O conhecimento e a esperteza veio do trabalho delas. É um tipo de escola pra quem estuda e pra quem não estuda. Pra quem lê e pra quem num lê. É um outro tipo de lugar."

O objeto de nossa atenção era o conhecimento que havia ali e o desenrolar da ações. Era o 'que coisas aconteciam' e o 'como'. A população não era objeto de nossas ações, mas influía constantemente nas decisões. Essa metodologia exigiu muito tempo e dedicação da equipe; mais que isso, exigiu uma certa 'curtição' e admiração por aquelas pessoas. Teve como pressupostos: compromisso, respeito e envolvimento com a população, postura muito diferente do tradicional distanciamento dos pesquisadores e técnicos. Havia uma decisão interior de busca de aproximação, interesse e bem-querer para com aquelas pessoas.

Fragmentos de diários de campo da nossa equipe de trabalho:

"Fui fazer uma entrevista numa casa em que morava uma mulher muito nova e uma criancinha de colo. Quase não falou. Fiquei chocada com tanta pobreza, parecia uma pessoa alienada, fora do mundo. Não sabia seu nome completo, a sua idade. Seu marido estava em São Paulo e não tinha notícias dele. O fogo estava apagado, a prateleira vazia, a casa seca sem nada. Não tinha vida, não tinha água, não tinha nada. Só o filho e a casa. Sem nenhuma perspectiva, sem nenhum ponto de apoio. Era ela e eu, uma estranha lhe fazendo perguntas que não sabia responder, entrando em sua casa, única coisa que tinha, querendo saber tudo, coisas que talvez nunca tivesse pensado, ou com que se preocupado, pois a vida dela é o dia de hoje. O amanhã, a gente dali não sabe se pode ver, se vai ter o que comer. Como se sobrevive, eu não sei. Disse-me que quando sai para trabalhar na roça ali por perto, que é a única forma de se ganhar algum dinheiro, deixa a criança com os outros. Fiquei pensando: o que será o futuro desta criança, será a mesma vida de sua mãe? Não sei."

"Parece que eu tenho um sentimento de nudez diante de uma realidade tão difícil. Mas todo cansaço e alguma renúncia que venho tendo de fazer neste trabalho, vale a pena quando eu penso na fisionomia das pessoas."

"Nem sei direito o que está acontecendo comigo, a partir deste trabalho em Cansanção. Só sei que estou mudando por dentro. Estou mudando meus pontos de referência, minha maneira de ver o mundo. Lá, com eles, descobri 
meus limites, os limites de meu saber, os limites do saber de minha ciência. Por outro lado, por incrível que pareça, no contato e na convivência com estas pessoas tão simples e tão sofridas, estou redescobrindo a alegria de viver. Estou dando e recebendo alento, ânimo, coragem. A paixão. Haverá coisa mais importante na vida?"

Os resultados deste tipo de processo vivido são muito difíceis de ser avaliados e comprovados. Entretanto, a observação do que aconteceu ali aponta algumas mudanças na vida da comunidade. Na base motivadora destas, está o tipo de relações entre a equipe e a população. A atitude de interesse, a valorização do saber popular, a qualidade da atenção, o relacionamento igualitário e principalmente o compromisso da equipe produziram entre os moradores um sentimento de autovalorização e confiança que impulsionam à ação e à organização. O sentimento de impotência diante dos problemas deu lugar a uma postura ativa, à vontade de mudar e à reivindicação junto aos poderes públicos por serviços essenciais. Para acontecer a transformação de uma postura passiva para uma postura ativa, entre as condições necessárias estão o despertar da auto-estima e o reconhecimento da própria dignidade.

Em meio a esta dinâmica vivencial, o controle da doença de Chagas foi se dando. Contribuíram para isso o processo educativo, a melhoria das casas e a erradicação dos triatomíneos, esta sendo fruto dos desmatamentos e da borrifação de inseticidas pela Sucam/FNS.

\section{Dez anos depois}

Em julho de 1996, voltamos a Cansanção. Foi uma festa nos dois lados: dos moradores e nosso. Apesar de ter sido uma passagem rápida, permitiu-nos observar muitas mudanças: presença de casas novas e adensamento do povoado principal, que conta com energia elétrica e água encanada; escola com mais de trezentas crianças matriculadas em classes de primeira a sexta séries, contando com 15 professoras, instalada em prédio em condições precárias; criação de duas creches e várias melhorias (engenho comunitário, água etc.) com o apoio da Ampliar (entidade filantrópica de desenvolvimento social ligada ao Fundo Cristão para Crianças); associação de moradores organizada e bem atuante; aumento de casas de comércio local (vendas); algumas antenas parabólicas e televisão; limpeza e cuidado com as casas; moradores locais que se destacam e/ou saem da cidade (vereador, presidente da Ampliar, noviça, seminarista, etc.); as crianças em geral parecem mais saídas, ativas e bem-nutridas; a migração sazonal para São Paulo continua, agora também por parte de algumas mulheres. Segundo informações da Fundação Nacional de Saúde, a transmissão da doença de Chagas na área está praticamente interrompida, não se registrando mais triatomíneos intradomiciliares e infecção de crianças abaixo de 14 anos de idade.

Entretanto, observamos algumas carências que ainda estão sem ser resolvidas ou encaminhadas. A primeira continua sendo o anseio da população por algum tipo de serviço de atenção básica de saúde na localidade, o sonho de ter um posto de saúde, com agente popular capacitado para ação preventiva, primeiros socorros, atendimentos simples e triagem de encaminhamentos. Há também o sonho de uma pequena farmácia comunitária e da visita de médicos. (Por que será que este anseio não foi resolvido? Será muito difícil um encaminhamento através do SUS? O SUS ainda tem futuro?) Outra carência era a água para as comunidades. Pudemos constatar que algumas já conseguiram realizar este anseio, por meio de uma ação da Ampliar, mas falta chegar às comunidades mais distantes do povoado central. Há um poço artesiano furado pela prefeitura com apoio da Rural Minas, mas falta fazer as ligações para as casas. Paralelamente, devido às altas taxas de parasitoses, especialmente da esquistossomose, está planejada uma parceria entre a prefeitura e a Fundação Nacional de Saúde na instalação de kits de saneamento básico.

Permanecem alguns questionamentos. Por que será que Cansanção apresentou aumento de número de moradias novas, enquanto em outras zonas rurais da região houve esvaziamento? Uma razão pode ser a tendência de povoamentos rarefeitos e dispersos tornarem-se mais adensados para facilitar a chegada de serviços essenciais como água, saneamento, escola, posto de saúde, energia elétrica, telefonia etc. Por outro lado, a migração sazonal parecer ter dado condições a alguns moradores de permanecerem na roça e fazerem casas novas.

Como estaria Cansanção no contexto maior do Município e do Vale do Jequitinhonha? Segundo os depoimentos dos membros do Conselho Municipal de Saúde de Minas Novas, a situação de saúde-doença na cidade ainda é muito precária, apesar de o atendimento médico ter melhorado com a abertura da policlínica na cidade. A "alimentação fraquinha demais", a falta de condições de higiene, a falta de água (que às vezes é obtida a três léguas de distância), a falta de instrução sobre o uso de sa- 
nitários, as parasitoses intestinais, são alguns dos problemas apontados pelos conselheiros. Disseram também que a assistência aos postos de saúde da zona rural ainda é difícil (faltam atendentes, locais adequados, profissionais capacitados e dispostos a dar assistência lá etc.). "A universidade não forma para o trabalho no interior, quando a prefeitura consegue profissionais, não estão preparados para enfrentar o que vão encontrar ali". Entretanto, o grande problema de saúde no Município é o mesmo em nível nacional: falta de recursos financeiros. Contrariamente ao setor educação, que apresentou tantas melhorias, o setor saúde não se desenvolveu como era preciso.

No entanto, hoje podemos notar, como eles mesmos disseram, a disposição de "um povo consciente de seus direitos e deveres de cidadãos, que luta sem cessar para que Cansanção continue progredindo cada vez mais".

Certamente, muitos aspectos importantes passaram despercebidos, não são notados numa visita assim tão rápida. Mas, sem dúvida, houve uma grande melhoria em Cansanção, a qual se deve principalmente à união e organização dos moradores, ao trabalho da Ampliar, e ao apoio da prefeitura, principalmente na questão da escola. As pessoas da comunidade falavam que tudo começou com o nosso projeto. Nessa visita houve uma recepção calorosa e cheia de alegria da comunidade à nossa equipe, revelando uma imagem muito positiva e reconhecida pelo trabalho realizado ali. Essa questão nos intrigou: quais as razões que levaram nosso projeto a ter aceitação e reconhecimento da comunidade? Podemos enumerar alguns motivos:

- termos chegado primeiro e trabalhado por mais de três anos sem descontinuidade em uma comunidade que nunca tinha recebido atenção social de qualquer outra instituição (comunidade 'virgem');

- termos chegado de modo diferente do que normalmente se chega: ouvindo e prestando atenção, visitando todas as casas, levando a sério o que se ouvia, valorizando a sabedoria popular, deixando-se contaminar pela alegria natural do povo do lugar;

- o caráter de 'pesquisa' que leva à sistematização e reflexão sobre a realidade e o pensar das pessoas, que não fica só no ativismo;

- a liberdade típica de projeto exploratório, sem instituição por trás com algum tipo de normatização e controle sobre o que estava ocorrendo ali;

- a continuidade da ação participativa comunitária, após o desligamento do projeto, feita pela Ampliar.
Finalmente, nada disso teria ocorrido se, há treze anos, quando se iniciou o processo, não houvesse ocorrido a acolhida generosa da comunidade, tão 'fraca' em recursos materiais e tão rica em potencialidades e valores humanos.

\section{Pistas para trabalhos de participação popular}

No correr da vida, tivemos muitas oportunidades de desenvolver trabalhos comunitários. Dessas experiências em seus erros e acertos, e do testemunho de homens e mulheres que nos marcaram com suas utopias e lucidez, pudemos aprender alguma coisa. Não são certezas e verdades prontas, mas algumas luzes e pistas que nos ajudam a caminhar na construção de um mundo mais humano e justo, que é o sentido subjacente de qualquer trabalho participativo.

\section{O modo de ver a vida das populações rurais e a ação de controle das endemias}

A primeira atitude do educador ao chegar a uma comunidade é de 'escuta' e consideração com a cultura local. Deve-se ter atenção e reconhecimento do saber próprio da população, construído com base em suas vivências e experiências diretas, saber que serve como ponto de identificação do grupo, de interpretação e representação do mundo a sua volta e veiculação de informações necessárias à sobrevivência. As pessoas simples geralmente estão mais atentas ao orador que ao discurso, pois sua cultura está baseada na prática da vida e não no mundo das idéias e dos livros.

Em conseqüência desta maneira de ver o mundo, podem-se observar pelo menos três aspectos que interessam quando se pensa em mobilização comunitária para o controle das endemias: vida colada no aqui e agora, visão integrada dos problemas e mobilização em torno de interesses concretos.

A vida colada no aqui e agora é uma característica do saber de pessoas que vivem no limite da sobrevivência. Esta maneira de viver é mais uma imposição da pobreza ou da fraqueza do que uma opção. Não se trata de 'por quê' ou 'para quê' preocupar-se com o futuro, mas de 'como'. Como permitir-se preocupar-se com um depois do amanhã, antes de suprir, mesmo precariamente, o hoje e o amanhã?

A vida cotidiana passa a ser "assim como o dia que amanhece e anoitece, como se vivesse acompanhando a natureza". Há uma visão mui- 
to localizada dos problemas da vida e de suas causas. O olhar não alcança muito longe. Nesta espécie de 'ética do tempo presente' sentem muitas vezes "um certo embaraçamento que não sabem explicar", sentem-se "atados" ou no "escuro". Muitas vezes, isso é interpretado pelos que chegam de fora como ignorância ou acomodação do povo da roça, mas na verdade não é. Esta visão que "não salta para além da própria sombra, não poderia marcar também a consciência dos limites sociais que sabe do possível da vida na vida possível? Sabendo-se que a pretensão impossível é uma das fontes primordiais de infelicidade, isto não seria sabedoria?" (Pedro Demo, Brasília, comunicação pessoal). Viver no aqui e agora permite a alegria do instante presente.

Com relação ao controle das endemias, isso precisa ser levado em conta. "Este viver dia-adia dificulta a percepção de projetos a longo prazo, ou de fenômenos que têm seus efeitos observados a grande distância de tempo e de suas causas" (Emma Rubín, Piura, Peru, comunicação pessoal). Este é o caso da doença de Chagas, que muitas vezes manifesta sua gravidade vinte anos depois da picada do triatomíneo.

As escolhas que a comunidade fez para seu programa de controle da doença de Chagas revelam uma visão integrada dos problemas. Ações de controle das endemias se entrelaçaram com atenção primária à saúde e com ações de desenvolvimento social, econômico, educativo e de cidadania. Também a expressão: "Aqui tem a fraqueza e a doença. Mas mais a fraque$z a$ ", ao entender a fraqueza como sinônimo de pobreza mais o sentimento de impotência, revela o modo de pensar a doença misturada à problemática da vida, raciocínio de totalidade. Isso pode ser uma indicação da importância da integração dessas ações, em nível de município, e revela a necessidade de parcerias entre entidades governamentais e não governamentais. A municipalização dos serviços de saúde é uma saída para o controle da doença de Chagas, principalmente na fase de vigilância epidemiológica.

Esta visão integrada dos problemas está correta, mas infelizmente a lógica do sistema passa pela especialização e pela diversificação dos serviços. Sabemos que a saúde e a doença, principalmente quando se trata das endemias, não são problemas isolados e individuais, são coletivos. Dependem de como um grupo de pessoas vive, como trabalha, o que come, quanto ganha, como mora. Dependem tanto do quanto estão vulneráveis e expostos aos vetores, como das características biológicas de seu corpo e dos serviços de saúde de que dispõem.
A mobilização em torno de interesses concretos, outra característica do saber popular, vem do senso de realidade e de concretude que o povo vive, refletindo a vida que leva. É natural que não se mobilize em torno de idéias, de informações novas ou da tradicional educação sanitária. No caso do controle das endemias, devem-se criar oportunidades para a população fazer experiências, ver e manusear instrumentos, para entender no concreto o ciclo de vida dos vetores e da doença.

A doença de Chagas, para os moradores de Cansanção é um problema entre tantos que têm que enfrentar no seu dia-a-dia. Diante do imediatismo em que vivem, da situação emergencial de sobrevivência no dia seguinte, essa doença não se constitui como o mais grave, urgente e importante problema. É apenas mais um, faz parte de um quadro mais amplo. Mas como um problema particular pode ser o caminho para o mais geral, a doença de Chagas pode ser o ponto de partida para uma ação mais ampla, se for encarada justamente dentro deste quadro maior, dentro da realidade do povo, integrada nela.

O longo processo de empobrecimento rouba do povo três coisas. Primeiro os seus bens, depois os direitos de participação na sociedade e, por último, rouba sua consciência. É como se a consciência ficasse grudada, encolhida. Quando chegam pessoas de fora que acreditam, confiam nele, identificando-se, a consciência parece renascer. O processo de recuperação se dá ao contrário, primeiro se dá o despertar da auto-estima e da consciência, que anima a participação na luta por melhores condições de vida.

Para ser coerente com a cultura popular, bem como com a complexidade e as interligações das carências e potencialidades do povo, o controle das doenças endêmicas deve passar por três vias ao mesmo tempo:

1) Remediando a situação encontrada: tratando os doentes, encaminhando para a aposentadoria quem não tem condições de trabalhar, aplicando inseticidas nos focos de vetores etc. Para isso, é necessária a integração em nível local (município) dos serviços de atenção médica, saneamento, controle de endemias, educação escolar. Experiências assim já vêm ocorrendo em alguns municípios que têm uma administração popular, atenta ao social.

2) Despertando as pessoas para a importância que cada um tem, para o reconhecimento da própria dignidade. Esse despertar não se dá pelo discurso, mas pela qualidade da atenção que se lhes dispensa, do relacionamento igualitário, da reflexão conjunta sobre a reali- 
dade em que vivem, da oportunidade de cogestão do programa, projetando utopias. Há assim o despertar da consciência que estava encolhida. É esse estímulo pessoal, essa mística que fazem caminhar, não a ciência. A educação popular é um instrumento para tal.

3) Atacando as causas: animando a organização do povo na luta por melhores condições de vida, aumento na produção agrícola, acesso a empregos, melhoria nas casas, direito à terra etc. Isso se dá pela organização da comunidade em conselhos, associações, fóruns, participação política...

\section{Alguns aspectos importantes do processo de participação popular}

A partir de nossa experiência em Cansanção, pudemos observar que o processo de investigação com a participação popular contém em si elementos didáticos. É confronto e comunicação entre sujeitos diferentes, processo recíproco de educação. Pode representar um espaço para o povo reconhecer a própria realidade, refletir coletivamente e, principalmente, para buscar alternativas de vida, dentro da realidade. Para o agente externo (pesquisador, educador ou técnico) pode representar uma oportunidade para crescer, mudar suas perspectivas e pontos de referência, em confronto com o diferente, se for aberto o suficiente para isso.

Envolvimento, compromisso, solidariedade são mais úteis e adequados que a postura de distanciamento, neutralidade e rigidez metodológica. Não se trata de inferências generalizadoras e relações lineares de causa/efeito. Mas de captar uma realidade aberta, incerta, relativa a tantos fatores, atenta à leitura e interpretação que os sujeitos fazem. Podem irromper repentinamente fenômenos imprevistos e incontroláveis que devem ser observados, registrados, acompanhados.

Envolvimento comunitário, estratégia de tantos programas governamentais de controle de endemias, pode ser entendido de duas maneiras diferentes. Geralmente é uma simples tática para levar a comunidade a fazer o que os técnicos de fora acham importante. Envolvimento e participação seriam confundidos com doutrinação ou como maneira de usar o povo para dar mais eficiência aos programas, ou para baratear seus custos. Levam muitas vezes ao raciocínio errôneo de que a auto-ajuda e a participação resolvem tudo, que os problemas locais são locais não só na sua expressão, mas também nas suas origens. Por outro lado, o envolvimento comunitário só pode ser eticamen- te aceito se for entendido como direito de cidadania, como participação popular nas decisões das políticas públicas, nas gestões dos programas, como controle social. Envolvimento entendido também como envolver e ser envolvido, como processo mútuo de educação, compromisso e solidariedade.

Para desencadear o processo de participação popular, a atitude de escuta é fundamental, como já foi dito. Escuta entendida como atenção concentrada e respeitosa que desperta a auto-estima. Mais do que ouvir, é preciso escutar com um 'terceiro' ouvido, escutar também o subjacente à fala.

“... o senhor me escute, me escute mais do que estou dizendo; e me escute desarmado. Muita coisa importante falta nome." (Rosa, 1970:86).

Não basta a aplicação de um bom questionário para se conhecer uma realidade, ele pouco ajuda na compreensão da vida que se leva ali. A capacidade de observar exige aprendizagem e exercício, exige sensibilidade, capacidade de se incorporar sem chamar a atenção.

Um programa democrático de controle de endemias é aquele que ouve cuidadosamente a população, informa corretamente, consulta ativamente, abre oportunidades de decisões conjuntas e não somente fica devolvendo ao povo os seus próprios problemas.

O diagnóstico só funciona se for assumido como autodiagnóstico. A participação dos moradores no levantamento de dados é imprescindível, mesmo correndo o risco de que estes dados não sejam tão científicos ou confiáveis.

O processo participativo consiste em fazer com que o povo comece a se reunir e se encontrar, para descobrir e discutir os seus problemas de vida e para encontrar uma solução: problemas concretos, soluções bem concretas.

É importante que a comunidade (por intermédio de suas lideranças, associação de moradores, escola etc.) tenha em mãos tudo que disser respeito à sua realidade ou ao trabalho ali desenvolvido (dados colhidos, diagnóstico sanitário, relatórios, análises, projetos etc.).

Alguns critérios são necessários na hora de selecionar os futuros educadores ou agentes populares de saúde para o trabalho participativo com comunidades carentes. Deve ser uma pessoa:

- com sensibilidade e capacidade de solidarizar-se e não 'seguir' sendo igual;

- não muito 'cheia de si', mas voltada para os outros, entusiasmada com o que faz;

- com capacidade de aprender com aquela realidade, de fazer perguntas e estabelecer relações, não considerando as situações como já conhecidas a priori; 
- que preste atenção em detalhes significativos que envolvem sutilezas e emoção dos participantes;

- que tenha capacidade de trabalhar em equipe, disponibilidade e compromisso;

- que exerça um papel de animação da comunidade, não de direção ou coordenação.

Por fim, uma regra de D. Werner: "É necessário que a pessoa se identifique com os pequenos, que seja uma pessoa sincera, com forte sentimento de justiça social, que trate os outros como iguais e se preocupe com os mais necessitados" (Werner, 1980:13). Tudo isso pode parecer muito ingênuo ou óbvio. São qualidades humanas ideais, difíceis de ser encontradas na mesma pessoa. Entretanto, é o que se busca. Para o trabalho comunitário, estas qualidades valem mais que as técnicas.

Estamos vivendo tempos de perplexidades e mudanças, às portas de um novo milênio. A solidariedade ativa ainda é um caminho de sentido para a vida, como tantos comitês da Ação da Cidadania inspirada por Betinho provaram ser. Solidariedade e participação popular estão de mãos dadas, pois não se pode erradicar a pobreza sem o pobre. É por isso que acreditamos nos resultados e no valor do trabalho de educadores que chegam de fora 'de braços e corações abertos'. Educadores que têm uma postura de profundo respeito para com as pessoas da comunidade, solidarizam-se com elas e dão um 'empurrãozinho' para que se organizem com mais entusiasmo a fim de construir um dia-adia mais feliz para o povo do lugar. É importante a crença no trabalho, o que cria oportunidades para o povo experimentar novas relações, descobrir a própria dignidade, enfim, "levantar as vistas". Isso tem acontecido por aí, em muitos lugares, com pessoas que acreditam e gostam de trabalhar junto com o povo.

Quem dera cada um de nós pudesse responder, quando perguntado, como D. Tereza respondeu:

"Eu? - Eu estou aí, compondo o mundo".

\section{Referências}

DIAS, R. B., 1986. Controle da Doença de Chagas em Cansanção, MG, Brasil: Pesquisa e Ação Comunitária. Belo Horizonte: Relatório ao TDR (UNDP/ WB/OMS). (mimeo.)

ROSA, J. G., 1970. Grande Sertão: Veredas. Rio de Janeiro: Livraria José Olympio.

WERNER, D., 1980. The village health care programme: community suportive or community oppressive? Contact, 57:1-16. 